\title{
Liaison psychiatry services in Wales
}

\author{
Tayyeb A. Tahir, ${ }^{1}$ Adam Watkins, ${ }^{2}$ Philip Slack, ${ }^{3}$ Phil Chick, ${ }^{4}$ William Lee, ${ }^{5}$ Andrea Gray ${ }^{6}$
}

BJPsych Bulletin (2019) 43, 17-20, doi:10.1192/bjb.2018.63

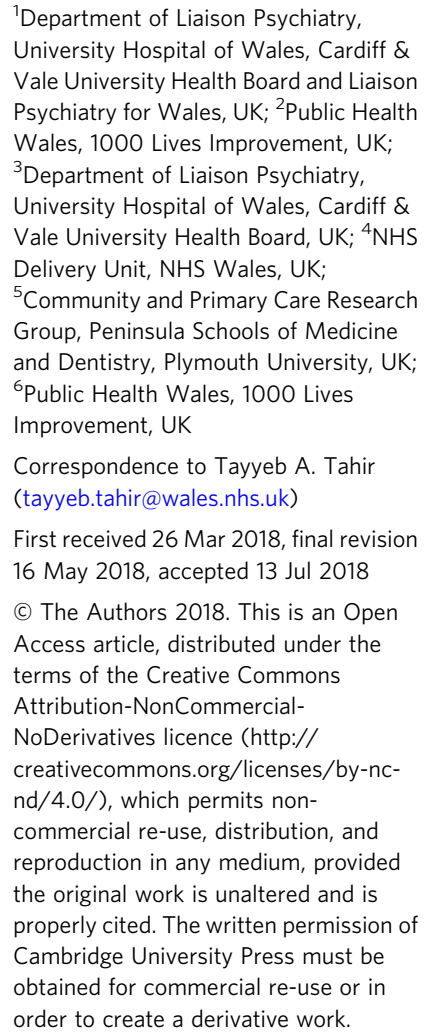

Aims and method Recent funding from Welsh Government for mental health has helped to develop liaison psychiatry services in Wales. Systematic data collection was undertaken to map the liaison psychiatry services in Wales in collaboration with the Royal College of Psychiatrists in Wales and Public Health Wales 1000 Lives Improvement. A questionnaire was designed and circulated to all the health boards in Wales to gather information to map liaison psychiatry services in Wales. Up-to-date information was confirmed in January 2018, via email.

Results Over the past 2 years, liaison psychiatry services have been set up in six out of seven health boards in Wales. Staffing levels have increased and the remit of services has broadened.

Clinical implications Mapping has highlighted that liaison psychiatry services in Wales continue to evolve. It will be important to continue to monitor these developments and their effects. Comparison with services in England will provide a useful comparison of service provision. A particular challenge will be to establish and monitor liaison psychiatry standards in Wales.

\section{Declaration of interest None.}

Keywords Liaison psychiatry; Wales; services; funding; staffing; standards.
In 2008, Wales had 2.6 full-time equivalent consultants in liaison psychiatry. ${ }^{1}$ Overall, where provided, liaison psychiatry services were not meeting the standards specified in the guidance 'Developing Models for Liaison Psychiatry Services'. ${ }^{2}$ Furthermore, three Welsh National Health Service (NHS) trusts did not provide a liaison psychiatry service. ${ }^{1}$ In 2009, 29 NHS organisations merged to form seven integrated health boards, providing all healthcare in Wales. ${ }^{3}$ Unlike England, there are no separate mental health trusts. Therefore mental health services are part of unified health boards that comprise both mental health and general hospitals. Every health board caters for a number of large and some smaller community hospitals within the geographical area covered by the respective health board.

A policy paper for England, 'Achieving Better Access to Mental Health Services by 2020', ${ }^{4}$ outlines the need to provide liaison psychiatry cover for all ages in the accident and emergency (A\&E) department. In 2012, the Welsh Government published 'Together for Mental Health', its 10-year strategy to improve mental health services. ${ }^{5}$ Within this document there was an acknowledgement that 'Improved liaison psychiatry services can ensure that mental health care needs are met for those people on general wards and reduce length of stay' (p. 65). ${ }^{5}$ The strategy required that all district general hospitals in Wales should have a liaison psychiatry team in place by March 2017.

In response to a request from NHS England, the national surveys of Liaison Psychiatry in England (LPSE) in collaboration with the Liaison Faculty of the Royal College of Psychiatrists charted the extent and growth of liaison psychiatry in England. ${ }^{6}$

In 2015 the Welsh Government allocated more than $£ 8 \mathrm{~m}$ of recurrent revenue investment to establish enhanced dementia, liaison psychiatry, psychological therapy and women and perinatal services. Additional funding was also made available to implement the legislative requirements of the Mental Capacity Act 2005.

\section{Method}

A collaboration between Public Health Wales 1000 Lives Improvement service, the Welsh Government, the NHS Delivery Unit and the Royal College of Psychiatrists in Wales systematically mapped liaison psychiatry services in 
Wales. This multi-agency quality improvement project did not require approval from an ethics committee.

A structured questionnaire was designed to gather information on the level of service provision, the make-up of teams by discipline, the type of service provided, the clinical areas and hospitals covered, the hours of working and any plans for further service development. The first draft of the questionnaire was piloted to test for suitability and for ease of data collection. Suggested changes were made to improve the quality of data collection, using Microsoft Excel. A lead clinician or manager (link person) with a remit for liaison psychiatry service was identified within each health board in Wales. The final questionnaire was disseminated electronically by the Public Health Wales 1000 Lives Improvement service to the link person in each health board. The data was collected and analysed with Microsoft Excel.

The collected information was presented in a meeting organised by the Public Health Wales 1000 Lives Improvement service attended by representatives from the liaison psychiatry services in Wales. In January 2018 the level of services across Wales were reconfirmed via email by each health board. This provided an opportunity to confirm or reconcile the information collected in the initial distribution of the questionnaire. The information collected in this mapping exercise is set out below.

\section{Results}

The six health boards in Wales with general hospitals responded to the questionnaire. The seventh health board, Powys Teaching Health Board, does not have an acute hospital and therefore did not respond. The liaison psychiatry services for working-age adults and older age adults were the main focus of this mapping exercise. The information gathered is summarised in Table 1.

\section{Service expansion}

There has been a significant increase in the availability of psychiatric liaison services in Wales in the past 10 years.

\begin{tabular}{|c|c|}
\hline $\begin{array}{l}\text { Health board (geographical } \\
\text { areas covered) }\end{array}$ & $\begin{array}{c}\text { Notes on service structure and } \\
\text { remit }\end{array}$ \\
\hline $\begin{array}{l}\text { Abertawe Bro Morgannwg } \\
\text { (Swansea, Neath Port Talbot) }\end{array}$ & $\begin{array}{l}\text { Services split geographically. One } \\
\text { area has a combined service, the } \\
\text { other has services split by age and } \\
\text { combined with other teams. }\end{array}$ \\
\hline $\begin{array}{l}\text { Aneurin Bevan (Gwent, } \\
\text { Monmouthshire) }\end{array}$ & $\begin{array}{l}\text { Services split by age, adult } \\
\text { combined with crisis resolution } \\
\text { home treatment team. }\end{array}$ \\
\hline Betsi Cadwaladr (North Wales) & $\begin{array}{l}\text { Single all-age service, meeting } \\
\text { Core } 24 \text { criteria. }\end{array}$ \\
\hline $\begin{array}{l}\text { Cardiff \& Vale (Cardiff and } \\
\text { Vale of Glamorgan) }\end{array}$ & $\begin{array}{l}\text { Services split by age, Poisons Unit } \\
\text { linked with the adult service. }\end{array}$ \\
\hline $\begin{array}{l}\text { Cwm Taf (Merthyr Tydfil, } \\
\text { Rhondda Cynon Taf) }\end{array}$ & Single all-age service. \\
\hline Hywel Dda (West Wales) & $\begin{array}{l}\text { Older adult service in place. Adult } \\
\text { being set-up. }\end{array}$ \\
\hline
\end{tabular}

Six Welsh health boards now provide a liaison psychiatry service for older adults, and all but one provide a working-age adult service. All services now operate in A\&E departments.

Table 1 shows the variation in the structure and remit of psychiatric liaison services across Wales. Some health boards have combined services covering working-age adults and older adults whereas others were split by age. One health board provides distinct geographical services. Two health boards have combined the crisis resolution home treatment team with the adult liaison psychiatry team. Table 2 identifies the total number of general hospital beds in each health board and the number of major general hospitals that make up each health board.

Betsi Cadwalder University Health Board provides a 24 hour liaison psychiatry service. This service meets the requirements of the Mental Health Partnerships' Core 24 model and is an accredited by the Psychiatric Liaison Accreditation Network (PLAN) ${ }^{7}$ service. Other services provide a broadly ' 9 to 5 ' service, although in many cases, this includes weekends and some services provide extended 12 or 14 hour cover of A\&E departments. Two health boards, Cardiff \& Vale University Health Board (C\&V UHB) and Abertawe Bro Morgannwg University Health Board, provide liaison psychiatry out-patient clinics. The liaison psychiatry service in Betsi Cadwalder University Health Board provides follow-up out-patient review appointments.

Dedicated intellectual disability liaison services (also known as learning disability in UK health services), substance misuse liaison services and child and adolescent liaison services were not the main focus of this survey. Some information was included in some of the responses. Two health boards have substance misuse liaison services as a stand-alone service.

\section{Staffing}

Table 2 summarises the staffing levels for the liaison services by discipline, together with total staffing levels in Wales in 2007. ${ }^{1}$ The table also identifies variation in the staffing levels between health boards; however, direct comparison is not possible given the different structures and remits of services. At this stage service provision cannot be explained by level of need or referral numbers in each health board as this information is only collected on a local level. To present the mapping more clearly and allow easier comparison, the data is set out by health board rather than by individual liaison teams or hospitals covered by the teams. In the two health boards where age-specific liaison teams operate, we have included the breakdown of these teams.

We identified that in the past 2 years there has been a considerable overall increase in the level of staffing within liaison psychiatry services in Wales. No health board has a liaison service comprising only nursing staff, whereas in 2007, this was the case in three out of eight liaison psychiatry services. Dementia support workers have been included in two old-age liaison psychiatry services. Five health boards include the provision of occupational therapy services. One old-age service includes support from a pharmacist. C\&V UHB previously established a nurse-led substance misuse liaison service consisting of three nurses. The health board 


\begin{tabular}{|c|c|c|c|c|c|c|c|c|c|c|}
\hline & \multirow{2}{*}{$\begin{array}{c}\text { Total in } \\
\text { Wales } 2007\end{array}$} & \multirow{2}{*}{$\begin{array}{c}\text { Total in } \\
\text { Wales } 2018\end{array}$} & \multirow{2}{*}{$\begin{array}{l}\text { Abertawe Bro } \\
\text { Morgannwg }\end{array}$} & \multicolumn{2}{|c|}{ Aneurin Bevan } & \multirow{2}{*}{$\begin{array}{c}\text { Betsi } \\
\text { Cadwaladr }\end{array}$} & \multicolumn{2}{|c|}{ Cardiff \& Vale } & \multirow{2}{*}{$\begin{array}{c}\text { Cwm } \\
\text { Taf }\end{array}$} & \multirow{2}{*}{$\begin{array}{l}\text { Hywel } \\
\text { Dda }\end{array}$} \\
\hline & & & & $\geq 65$ & $<65$ & & $\geq 65$ & $<65$ & & \\
\hline $\begin{array}{l}\text { Average daily available } \\
\text { beds, } 2016-2017^{8}\end{array}$ & & & 1745 & \multicolumn{2}{|c|}{1577} & 1975 & \multicolumn{2}{|c|}{1487} & 1067 & 1011 \\
\hline Major hospitals & & & 4 & \multicolumn{2}{|c|}{3} & 3 & \multicolumn{2}{|c|}{4} & 2 & 4 \\
\hline Consultant & 2.6 & 9 & 2 & 1 & & 3 & 1 & 1 & 1 & \\
\hline Other medical staff & 3.6 & 7.7 & 1 & 0.8 & 0.1 & 3 & 0.8 & 1 & 1 & \\
\hline Nurses band 7 & 19.7 & 22.5 & 4 & 2 & 2 & 3 & 2 & 5.5 & 2 & 2 \\
\hline Nurses band 6 & & & 11.25 & 10.8 & $21^{a}$ & 49 & 2.5 & & 8 & 4 \\
\hline Nursing band 5 and below & & & & & & 18.8 & 7 & & 6 & \\
\hline Psychology & 2.4 & 4.5 & 0.5 & & & 1.5 & 1 & 0.5 & 1 & \\
\hline Occupational therapists & & & 3 & & & 1 & 1 & & 2 & 2 \\
\hline Dementia support workers & & & & 8.5 & 1 & & 2 & & & \\
\hline Admin staff & & & 6 & 2 & 1 & 2.1 & 1 & 0.8 & 2.3 & 1 \\
\hline Pharmacists & & & 1.5 & & & 0.4 & 0.4 & & & \\
\hline
\end{tabular}

Average daily bed availability for 2016-2017. Staffing numbers for old age ( $\geq 65$ ) and working age adult $(<65)$ teams are split for Aneurin Bevan Health Board and Cardiff $\&$ Vale University Health Board. For all other services, establishment numbers are presented as one team.

a. Aneurin Bevan Crisis Resolution Home Treatment Team covers liaison psychiatry work.

also has a dedicated service for people presenting to the $A \& E$ department with alcohol-related issues, which was developed with separate public health funding. Betsi Cadwalder University Health Board provides two nurses dedicated to an alcohol misuse service within its liaison psychiatry service.

\section{Discussion}

This is the first survey of liaison psychiatry services in Wales since additional funding was provided by the Welsh Government in 2015. At a national level, medical staffing has trebled and nurse staffing has doubled since 2007. This mapping process identified the progress in establishing multi-disciplinary services with an increase in the number of nurses, dedicated psychology support, the inclusion of occupational therapists and dementia support workers with additional consultant posts. This mapping exercise was undertaken using the available resources, with no additional funding for this work. We achieved this through multi-agency collaborative work between the Public Health Wales 1000 Lives Improvement service, NHS Wales Delivery Unit and the Royal College of Psychiatrists in Wales.

Historically some health boards had no specific liaison psychiatry teams and relied on community mental health teams and duty psychiatrist cover. In some areas a collaborative 'goodwill' arrangement existed between consultant colleagues to provide cover for the mental health needs of patients in acute hospitals where no specific cover for liaison psychiatry teams was in place. For these health boards, the new funding from the Welsh Government for liaison psychiatry has been of particular significance. In certain instances, the duty system and crisis teams continue to provide cover to A\&E departments out of hours. In addition to government-funded developments, locally funded initiatives have also enhanced these services. This survey did not collect detailed information on these local arrangements or the division of government funding for setting up these services, which is a potential limitation.

The health boards in Wales had autonomously established services according to local needs and requirements. Wales is diverse in its geography and demography, with a mix of rural and urban centres, and the size of geographical areas covered by the individual health board varies. These factors could have influenced the manner in which liaison psychiatry teams have been established by health boards.

The previous survey undertaken in 2008 reported that, in total, there were only two relatively well-established services in Wales: Cardiff and Swansea. ${ }^{1}$ In North Wales, a service delivered by a less than full-time consultant with some nursing support existed. Before funding from the Welsh Government becoming available, Cardiff and Swansea had set up old-age liaison psychiatry services. Aneurin Bevan University Health Board piloted the old-age Rapid Assessment, Interface and Discharge ${ }^{9}$ model in the Royal Gwent Hospital and this is now also the model used by the old-age liaison service in C\&V UHB.

A liaison psychiatry team should include a consultant psychiatrist, mental health nurses and a psychologist as a core part of this team. Recommended minimum staffing numbers vary with the size of the hospital and type of service. ${ }^{2}$ Published models of liaison psychiatry are named Core, Core 24, Enhanced 24 and Comprehensive. For example, the minimum numbers for a Core liaison psychiatry service covering around 500 beds are two whole-time equivalent consultant psychiatrists and eight whole-time equivalent nurses, in addition to other staff.

The PLAN ${ }^{7}$ has provided quality standards for liaison psychiatry services. Since LPSE-1 was undertaken, there have been two further surveys of liaison psychiatry in England, with response rates of $100 \%$ and $97 \%$, respectively. The LPSE has charted the growth of liaison psychiatry in England against the government commitment to establish 
liaison psychiatry in every acute hospital with an A\&E department in England by 2021, with half of these meeting the Core 24 specifications. A fourth survey, LPSE-4, is planned for 2018.

The challenge within Wales will be to evaluate the effect of the newly established liaison psychiatry services. Information currently available suggests that different health boards have invested in developing services in line with their local vision and perceived requirements. Within the relatively small sample of Welsh health boards, there is diversity in the type of liaison psychiatry services provided.

We recommend that information for the next logical phase should be obtained on referral rates to these services. Furthermore, it would be prudent to set standards for liaison psychiatry services in Wales. These standards could be similar to the standards that have evolved in England or bespoke liaison psychiatry standards could be developed for Wales. Hence, further work might also involve assessment of adherence to the agreed standards.

There is an opportunity to learn from the experiences in England. An important lesson from the experience of the LPSE process in England is the need to repeat the mapping exercise over a period of time to assess progress. Moreover, comparison with services in England may emphasise the need for future funding to develop liaison psychiatry services in Wales.

There is an opportunity to gather further data on referrals, standards, patient experience, outcome measures and the evolution of services. There is also an opportunity for health boards to learn from services with a well-established substance misuse liaison service and intellectual disability liaison service.

Liaison psychiatry for children and adolescents in Wales, as in England, is less well developed. Furthermore, investment in a liaison psychiatry service for the specialist Velindre Cancer Centre will need to be considered, as will the arrangements in Powys Teaching Health Board, which does not have any acute general hospitals.

It is anticipated that the development in Welsh liaison psychiatry services will attract trainees to liaison psychiatry for foundation, core and higher training. Previously there were only two services in Wales that provided higher training leading to endorsement in liaison psychiatry.

In conclusion, liaison psychiatry services in Wales are developing and evolving. It would be prudent to monitor this evolution with a view to setting standards, surveying adherence to the standards and monitoring the referrals for an outcome-oriented evaluation of these services. Already, in collaboration with Public Health Wales and the NHS Delivery Unit, plans are in place for developing the governance to address the recommendations discussed in this paper.

\section{About the authors}

Tayyeb A. Tahir is a Consultant Liaison Psychiatrist in the Department of Liaison Psychiatry, University Hospital of Wales, Cardiff \& Vale University Health Board and National Clinical Lead for Liaison Psychiatry for Wales, UK. Adam Watkins is an Information Analyst with Public Health Wales, 1000 Lives Improvement, UK. Philip Slack is an ST5 in Old Age Psychiatry in the Department of Liaison Psychiatry, University Hospital of Wales, Cardiff \& Vale University Health Board, UK. Phil Chick is Assistant Director of the NHS Delivery Unit, NHS Wales, UK. William Lee is an Associate Professor in psychiatry and a Consultant Psychiatrist with the Community and Primary Care Research Group, Peninsula Schools of Medicine and Dentistry, Plymouth University, UK. Andrea Gray is the Mental Health Development Lead for Wales at Public Health Wales, 1000 Lives Improvement, UK.

\section{Acknowledgements}

We are grateful to all the liaison psychiatry teams in the health boards who contributed to information for this paper.

\section{References}

1 Sakhuja D, Bisson Jl. Liaison psychiatry services in Wales. Psychiatrist 2008; 32(4): 134-36.

2 Aitken P, Robens S, Emmens T. Developing Models of Liaison Psychiatry Services. Strategic Clinical Network for Mental Health, Dementia and Neurological Conditions South West, 2014 (https://mentalhealthpartner ships.com/resource/developing-models-for-liaison-psychiatry-services).

3 NHS Wales. NHS in Wales - Why We are Changing the Structure. Welsh Government, 2009 (http://www.wales.nhs.uk/documents/NHS\%20 Reform\%20leaflet_October\%202009.pdf).

4 Department of Health. Achieving Better Access To Mental Health Services By 2020, 2014 (https://www.gov.uk/government/publications/mentalhealth-services-achieving-better-access-by-2020).

5 Welsh Government. Together for Mental Health, 2012 (https://gov.wales/ docs/dhss/publications/121031tmhfinalen.pdf).

6 Barrett J, Aitken P, Lee W. Report of the 2nd Annual Survey of Liaison Psychiatry in England. NHS England and the National Collaborating Centre for Mental Health, 2015 (https://www.crisiscareconcordat.org. uk/wp-content/uploads/2015/10/2a-Report-of-the-2nd-Annual-Surveyof-Liaison-Psychiatry-in-England-20-.pdf).

7 Psychiatric Liaison Accreditation Network (PLAN). PLAN Members. Royal College of Psychiatrists, 2018 (https://www.rcpsych.ac.uk/workinpsychiatry/qualityimprovement/qualitynetworks/liaisonpsychiatry/plan/ planmembers.aspx).

8 StatsWales. NHS beds. Welsh Government, 2017. (https://statswales.gov. wales/Catalogue/Health-and-Social-Care/NHS-Hospital-Activity/NHS-Beds).

9 Tadros G, Salama R, Kingston P, Mustafa N, Johnson E, Pannell R, et al. Impact of an integrated rapid response psychiatric liaison team on quality improvement and cost savings: the Birmingham RAID model. Psychiatrist 2013; 37(1): 4-10.

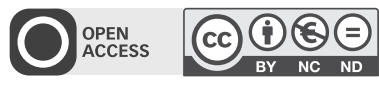

